\title{
Miguel Ángel de Quevedo y el proyecto de conservación hidrológica forestal de las cuencas nacionales de la primera mitad del siglo XX, 1900-1940*
}

Juan Humberto Urquiza García

Profesor de la Facultad de Filosofía y Letras de la Universidad Nacional Autónoma de México (México). Correo electrónico: jhurquiz@gmail.com. El autor es Doctor en Historia de la Universidad Nacional Autónoma de México (México). Entre sus publicaciones recientes tenemos: "Controlar para no entregar: la prensa de Balbina y la geopolítica ambiental brasileña", en Relaciones internacionales y estudios de geopolítica en nuestra América, eds. Ricardo Domínguez y Fabián Campos (México: Ediciones Eón-Posgrados en Estudios Latinoamericanos-UNAM, 2012). Entre sus líneas de investigación están los temas de historia ambiental e historia de la ciencia y la tecnología.

Recibido: 25 de julio de 2015

Aprobado: 14 de septiembre de 2015

Modificado: 12 de noviembre de 2015

Artículo de investigación e innovación

DOI: http://dx.doi.org/10.15648/hc.26.2015.8

Este artículo forma parte del proyecto "Ciencia forestal, propiedad y conservación para el desarrollo nacional. Los estudios y trabajos ambientales de Miguel Ángel de Quevedo: una historia de su influencia en las políticas de consevación de las cuencas hidrológicas (1890-1940)", financiado por el Consejo Nacional de Ciencia y Tecnología, CONACyT (México).

Esta publicación está bajo una licencia Creative Commons Reconocimiento-Compartir Igual 3.0

\section{(cc) BY-SA}




\title{
Miguel Ángel de Quevedo y el proyecto de conservación hidrológica forestal de las cuencas nacionales de la primera mitad del siglo XX, 1900-1940
}

\section{Resumen}

El debate sobre la desforestación en México durante la segunda mitad del siglo XIX ejemplifica cómo las élites científicas tenían claros los problemas derivados de las talas masivas. Las tesis del conservacionismo hidrológico forestal de las cuencas, impulsado por el ingeniero Miguel Ángel de Quevedo, probaron que en México se desarrolló un proyecto de conservación que antecedió a las propuestas de la Conferencia Norteamericana de Conservación de Recursos Naturales. La participación de Quevedo en esa Conferencia incorporó la perspectiva mexicana en las resoluciones y su aplicación en nuestro país por parte del grupo conservacionista que él encabezó entre 1917-1940.

Palabras clave: Miguel Ángel de Quevedo, cuencas, conservación, desforestación, propiedad.

\section{Miguel Angel de Quevedo and the forest hydrological conservation project of national watersheds in the first half of the twentieth century, 1900-1940}

\begin{abstract}
The debate around deforestation in Mexico during the second half of the nineteenth century gives us an example of how clear the problems arised by massive wood cutting were for the scientific elites. The thesis about hidrological conservacionism of forest watersheds, encouraged by engineer Miguel Angel de Quevedo, proved that a conservation project that preceded the proposals of the North-american Conference for Natural Resources Conservation had been developed in Mexico. The participation of Quevedo in that Conference incorporated the mexican perspective in the resolutions and its aplication in our country, oriented by the conservacionist group he headed between 1917-1940.
\end{abstract}

Key words: Miguel Angel de Quevedo, watershed, conservation, deforestation, property.

Miguel Angel de Quevedo ea conservação da floresta projecto de bacias hidrográficas nacionais na primeira metade do século XX, 1900-1940

Resumo

O debate sobre a deflorestamento no México durante a segunda metade do século XIX exemplifica a forma em que as elites científicas tinham clareza sobre os proble- 
mas derivados do corte massivo de árvores. As teses do conservacionismo hidrológico florestal sobre as bacias, impulsionadas pelo engenheiro Miguel Ángel de Quevedo, provaram que o México tinha desenvolvido um projeto de conservação que antecedeu às propostas da Conferência Norte-americana de Conservação de Recursos Naturais. A participação de Quevedo nessa Conferência incorporou a perspectiva mexicana nas resoluções e a sua aplicação em nosso país por parte do grupo de conservação que ele encabeçou entre 1917-1940.

Palabras-chave: Miguel Angel de Quevedo, bacias hidrográficas, conservação, desmatamento, propriedade.

\section{Miguel Ángel de Quévedo et le projet de conservation hydrologique fores- tière des bassins nationaux de la première moitié du XX siècle, 1900-1940}

\section{Résumé}

Le débat sur le déboisement au Mexique pendant la deuxième moitié du XIX $^{\circ}$ siècle montre à quel point les élites scientifiques possédaient une vision claire des problèmes découlant de la coupe massive d'arbres. Les thèses sur la conservation hydrologique des bassins nationaux lancée par l’ingénieur Miguel Ángel de Quevedo ont montré que s'est déroulé au Mexique un projet de conservation qui a précédé les propositions de la Conférence Nord-américaine de Conservation des Ressources Naturelles. La participation de Quevedo à cette Conférence a permis d'incorporer la perspective mexicaine aux résolutions et de l'appliquer dans notre pays à travers le groupe qui encourageait la conservation et dont il a été le représentant entre 1917 et 1940.

Mots-clés: Miguel Ángel de Quévedo, bassins, conservation, déforestation, propriété.

\section{INTRODUCCIÓN}

Uno de los eventos más relevantes para el desarrollo de la política conservacionista en México, durante la primera mitad del siglo XX, tuvo lugar del 18 al 24 de febrero de 1909 en la ciudad de Washington, D.C. Por iniciativa del entonces presidente Theodore Roosevelt fue organizada la Conferencia Internacional Norteamericana sobre Conservación de los Recursos Naturales, a la cual fue invitado a participar el gobierno mexicano. Durante aquellos días los delegados de los distintos países convocados, Canadá, 
la provincia de Terranova, los Estados Unidos y México, expusieron y debatieron sus propuestas, mismas que posteriormente fueron aprobadas en el pleno de la reunión de las partes. Dichas ideas quedaron plasmadas en un documento conjunto intitulado "Resoluciones de la Conferencia", las cuales conformaron el programa sobre el cual trabajaría la segunda generación de conservacionistas mexicanos ${ }^{1}$.

En este artículo se intentará demostrar que las ideas desarrolladas por Miguel Ángel de Quevedo ${ }^{2}$ fueron incorporadas en las Resoluciones de la Conferencia y sirvieron posteriormente para impulsar diversas medidas de conservación hidrológica forestal en las cuencas de México durante los años de 1909-1940. Para alcanzar este objetivo hemos dividido este trabajo de la siguiente manera. En el primer apartado se expondrán de forma sintética los rasgos más representativos del debate sobre la desforestación en México durante la segunda mitad del siglo XIX, lo que nos permitirá ejemplificar cómo en nuestro país las élites científicas tenían claros los problemas derivados de las talas masivas y la tensión entre propiedad privada y conservación forestal. En el segundo apartado se usarán las tesis del conservacionismo hidrológico forestal, impulsado por el ingeniero Miguel

1 Esta segunda generación de conservacionistas mexicanos son el grupo de ingenieros, botánicos, naturalistas, arquitectos, agrónomos y personas ilustradas que trabajaron junto al ingeniero Miguel Ángel de Quevedo y Zubieta desde la constitución de la Junta Central de Bosques y Arbolados, en 1904, hasta la extinción del Departamento Autónomo Forestal y de Caza y Pesca, ocurrida en 1940.

2 La propuesta que se presenta en este artículo sobre la figura de Miguel Ángel de Quevedo y sus trabajos intentan mostrar una óptica distinta de los estudios realizados por autores norteamericanos y europeos: mientras que ellos parten del análisis histórico de su política ambiental para aplicar ese modelo al estudio de la de otras latitudes; la que proponemos busca la genealogía del pensamiento ambiental mexicano en sus particularidades y circunstancias. Los trabajos a los que nos referimos, en orden de aparición, son: Lane Simonian, La defensa de la tierra del jaguar. Una historia de la conservación en México (México: Instituto Nacional de Ecología, 1998); Emily Wakild, "«It is to preserve life, to work for the trees». The steward of Mexico's forests, Miguel Angel de Quevedo, 1862-1946”. Forest History Today, primavera-otoño (2006): 4-14; Christian Boyer, "Revolución y paternalismo ecológico: Miguel Ángel de Quevedo y la política forestal en México, 1926-1940", Historia Mexicana, v. LVII, No. 1 (2007): 91-138; Matthew Vitz, "La ciudad y sus bosques. La conservación forestal y los campesinos en el valle de México, 1900-1950", Estudios de Historia Moderna y Contemporánea de México, No. 43 (2012): 135-172; Christian Boyer y Emily Wakild, "Social Landscaping in the Forests of Mexico: An Environmental Interpretation of Cardenismo, 1934-1940", Hispanic American Historical Review, v. 92, No. 1 (2012): 73-106; Vicente Casals Costa, "El ingeniero Miguel Ángel de Quevedo y los inicios de la electrificación en México". En Actas del Simposio Internacional Globalización, innovación y construcción de redes técnicas urbanas en América y Europa, 1890-1930. Editores Vicente Casals y Horacio Capel, (Barcelona, 2012) 1-26. Disponible en http://www.ub.edu/ geocrit/Simposio/cCasals_Elingeniero.pdf 
Ángel de Quevedo, lo que nos ayudará a demostrar que México tenía un proyecto de conservación anterior a la Conferencia, cuya base eran las cuencas hidrológicas. En la tercera parte se retomará la participación de Miguel Ángel de Quevedo en la Conferencia Norteamericana de Conservación de los Recursos Naturales y sus resoluciones, con lo que podremos comprobar la incorporación de la perspectiva mexicana de conservación a las Resoluciones de la Conferencia y la manera en que fueron utilizadas para impulsar el proyecto del grupo conservacionista, encabezado por el mismo Quevedo, durante los años de 1917-1940. En la última parte se retomarán las acciones más representativas que nos permitan demostrar la implementación en México de las Resoluciones de la Conferencia.

\section{LAS ÉLITES CIENTÍFICAS Y EL DEBATE SOBRE LA DESFORESTACIÓN}

El 5 de septiembre de 1794 José Antonio Alzate expuso que los pobladores europeos y los naturales que habitaban la Nueva España contaban con grandes extensiones de montes poblados de bosques, con los que habían obtenido grandes cantidades de carbón para cubrir sus necesidades. Asimismo, advirtió a la Corona el grave riesgo que implicaría para la economía minera de la Nueva España no contar con el suministro necesario de madera tanto para la fundición de los metales como para las actividades domésticas. José Antonio Alzate explicaba que "los montes de día en día se aniquilan, y no se verifican nuevas plantaciones de árboles, llegará el día en que los pobladores de este vasto y extenso país suspiren por combustibles" un material que "acompaña las necesidades de comer y beber" ${ }^{3}$. Esta advertencia tardaría casi 70 años en hacerse realidad y convertirse en un problema socialmente relevante para las élites científicas en nuestro país.

El pensamiento científico de Alzate nos permite demostrar que la preocupación por el deterioro de la naturaleza y sus recursos ha estado presente en el debate mexicano desde hace más de dos siglos. Sin embargo, fue hasta la segunda mitad del siglo XIX cuando naturalistas, botánicos, químicos, ingenieros, médicos y abogados señalaron de manera puntual que existía

3 José Antonio Alzate y Ramírez, Proyecto del Br. José Alzate Ramírez sobre el descubrimiento y uso del carbón mineral (transcripción). (México: Cuadernos de Quipu, 1988), 71. 
una tensión entre las actividades humanas y la capacidad de la naturaleza para regenerarse. Esta tensión que advirtieron los científicos mexicanos puso en duda la idea de cornucopia nacional. Este cuestionamiento a la noción de riqueza inagotable y una tierra privilegiada también provocaría que muchos liberales tomaran conciencia de la importancia que tenía el trabajo del ser humano en materia de conservación y reforestación para el bienestar del país, lo que detonó una profunda discusión en las élites científicas mexicanas.

Uno de los puntos principales en el debate fue la propiedad particular y el papel que tendría que asumir el Estado ante el uso, abuso y destrucción que los propietarios hacían de los recursos silvícolas. En esta discusión destacaron los trabajos de Manuel Payno e Ignacio Ramírez, quienes reconocían que la desforestación era un problema grave, aunque sus posturas para solucionarlo tenían diferencias de fondo. Para Payno era necesario limitar el abuso de los particulares sobre los bosques, utilizando como mecanismo el derecho administrativo ${ }^{4}$. Este planteamiento se apoyaba en las tesis científicas de la época que reconocían la importancia que tenían los bosques para el régimen de las aguas y la climatología. En contraposición estaban las tesis de Ignacio Ramírez, quien no creía que el Estado debería intervenir en la materia. Ramírez pensaba que los intereses económicos de los individuos eran suficientes para detener el problema y que esto se lograría generando incentivos monetarios para que los particulares conservaran sus bosques ${ }^{5}$. Las ideas de Ramírez se sustentaban también en una perspectiva científica: no aceptaba la importancia de los bosques en la regulación del clima ni la hidrología. Podemos decir que estas dos posturas dejan ver un profundo debate por la nación: la que defendería los intereses particulares-privados y la que apoyaba el interés social y promovía la participación del Estado para controlar el uso, abuso y destrucción de los bosques.

4 Manuel Payno, "Bosques y Arbolados", Boletín de la Sociedad Mexicana de Geografía y Estadística, 2a Época, t. II, (1870): 77-91.

5 Ignacio Ramírez et al., "Bosques y Arbolados", Boletín de la Sociedad Mexicana de Geografía y Estadística, 2a Época, t. II, (1870): 14-24. 
En el debate se pueden identificar y reconocer otras voces científicas como la de Pio Bustamante Rocha ${ }^{6}$, Ramón Almaraz ${ }^{7}$, Leopoldo Río de la Loza ${ }^{8}$, Gabriel Hinojosa ${ }^{9}$, Eugenio Frey ${ }^{10}$, Mariano Bárcena ${ }^{11}$, Isidoro Epstein $^{12}$, Manuel Villada, Eduardo Armendariz y Fernando Altamirano ${ }^{13}$. Un elemento común entre estos hombres de ciencia es que reconocieron, a pesar de sus diferencias disciplinarias y su labor en diferentes etapas de la segunda mitad del siglo XIX, que la pérdida de la cubierta forestal tenía graves implicaciones para la nación. Podemos decir que en todos los trabajos desarrollados por estos científicos mexicanos se reconoce que las talas inmoderadas estaban provocando cambios en el régimen de las lluvias y de las corrientes de aguas superficiales, en la higiene pública, en la erosión de los suelos y en el clima.

El debate científico también expresó una postura político-ideológica: en sus trabajos se puede ver el constante reclamo hacia las autoridades para que estas intervinieran y frenaran el abuso que los particulares hacían de los recursos silvícolas, principalmente las compañías mineras y ferrocarrileras. En este sentido podemos argumentar que las perspectivas de los científicos participaron en el debate por la nación, puesto que muchos de ellos sostenían que la conservación de los bosques era una necesidad imperante para el bienestar público.

6 Pio Bustamante Rocha, Discurso sobre el establecimiento de la vegetación en la superficie del globo, (México: El Siglo XIX, 29 de mayo de 1851), s/p.

7 Ramón Almaraz, Memorias de los trabajos ejecutados por la Comisión Científica de Pachuca en el año de 1864 (México: Imprenta de J. M. Andrade y F. Escalante, 1865).

8 Leopoldo Río de la Loza, "Proyecto de Ordenanzas de bosques, de arbolados y de exportación de maderas", en Escritos de Leopoldo Río de la Loza, (comp.) Juan Manuel Noriega (México: Secretaría de Instrucción Pública y Bellas Artes, Imprenta de Ignacio Escalante, 1911).

9 Gabriel Hinojosa, Memoria sobre la utilidad de los bosques (México: El Siglo XIX, 31 de agosto de 1874), 1-2.

10 Eugenio Frey, Utilidad de los Bosques. Estudio Presentado a la Secretaría de Fomento en 1882, (México: Imprenta y Fototipia de la Secretaría de Fomento, 1907).

11 Mariano Bárcena, Silvicultura. Breves consideraciones sobre explotación y formación de los Bosques. Estudio Presentado a la Secretaría de Fomento (Tepic: Tipografía de la V. de Legas, 1892).

12 Isidoro Epstein, "La Tala inmoderada de los Montes. Estudio y proposiciones leídos en la Sociedad de Geografía y Estadística, por su autor, en la sesión del 5 de septiembre del presente”, El Nacional, México, 10 de abril de 1894, 2.

13 Manuel M. Villada et al., Concurso científico. Sociedad de Historia Natural. Discursos publicados en la sesión del día $1^{\circ}$ de agosto de 1895 (México: Oficina Tipográfica de la Secretaría de Fomento, 1895). 
La opinión de los científicos mexicanos sobre las implicaciones de las talas masivas llegó a la prensa, la cual sirvió como vehículo para difundir las tesis que irían normando la perspectiva sobre el problema. Durante los años de 1870-1900 un gran número de editorialistas y columnistas preocupados por la desforestación, utilizaron las ideas científicas que aceptaban que la pérdida de grandes masas forestales estaba provocando cambios significativos en diferentes niveles como alteraciones climáticas, problemas de higiene pública, escasez de combustible y materiales, irregularidad del régimen de las lluvias y pérdida y erosión de los suelos cultivables, para presionar al gobierno a adoptar medidas jurídicas y prácticas para solucionar el problema.

La prensa jugó un papel muy importante en la difusión del problema, pues gracias a su trabajo se dio a conocer a la sociedad que se encontraba alejada de las ideas científicas. En este nivel se ejerció un reclamo permanente hacia las autoridades para que tomaran cartas en el asunto: la prensa constantemente exigía que se implementaran leyes para solucionar la desforestación.

Los problemas derivados de las talas masivas fueron poco a poco preocupando a las élites políticas. En este orden de ideas podemos decir que las tesis expuestas por los científicos se fueron traduciendo en una serie de políticas públicas de corto alcance para la magnitud del problema. El gobierno implementó distintas iniciativas prácticas, en diferentes escalas, para intentar detener la desforestación. Estas acciones no arrojaron buenos resultados, pues el conflicto siguió avanzando. Las medidas adoptadas fueron limitadas y en gran medida resultado de la presión que ejercían los grupos científicos desde la prensa. El impacto social de dichas acciones gubernamentales se puede observar en los proyectos de reforestación a pequeña escala, las leyes, reglamentos y circulares emitidos, los decretos de reservas forestales y políticas como la del "Día de los árboles", esta última de carácter no obligatorio.

Las élites fueron incorporando y analizando los diversos problemas derivados de la desforestación. En este relato podemos ver una parte de la historia o la genealogía del pensamiento conservacionista mexicano de la segunda mitad del siglo XIX, reflejo de nuestra tradición. Esto es relevante 
porque nos permite comprender que hay una continuidad, de larga duración, entre los trabajos de la primera generación de conservacionistas -los antes mencionados-y aquellos impulsados por Miguel Ángel de Quevedo en el siglo XX. Nos permite demostrar que el proyecto de conservación de las cuencas nacionales promovido desde 1901 por el mismo Quevedo tiene sus raíces y tradición en las preocupaciones científico-sociales decimonónicas por la desforestación del territorio nacional. También nos ayuda a comprender que la lucha por la conservación, que se expresó en la política y en las leyes posrevolucionarias, es un proceso de continuidad y consolidación de las ideas del conservacionismo social mexicano. En este sentido podremos demostrar que los Parques Nacionales, Reservas Forestales, Zonas Protectoras Forestales, Zonas Protectoras Forestales Vedadas y Reservas Forestales de Repoblación respondieron a la necesidad de conservar las zonas funcionales altas, medias y bajas de las cuencas hidrológicas del territorio. Estas zonas estaban directamente relacionadas con el proyecto agrícola e industrial que se desarrolló principalmente en la Mesa Central. De esta manera, argumentamos que el conservacionismo mexicano del siglo XX se fundamentó en la conservación y reforestación de los bosques para dar estabilidad a las cuencas y sus procesos hidrológicos, siempre considerando la justicia social.

\section{Miguel Ángel de Quevedo y la conservación forestal de LAS CUENCAS HIDROLÓGICAS}

Desde la segunda mitad del siglo XIX los grupos científicos reconocieron la importancia de la conservación forestal; sin embargo, fueron los trabajos de ingeniería aplicada los primeros en exponer la importancia que tenía la conservación hidrológica forestal de las cuencas para garantizar el desarrollo agrícola e industrial del país. Estas ideas sirvieron como guía de las políticas que se implementaron en México entre 1900 y 1940. En esta historia podemos reconocer los trabajos del ingeniero Miguel Ángel de Quevedo como el principal impulsor de dicho enfoque.

Después de haber cursado sus estudios profesionales en la Escuela de Puentes y Calzadas en París, Miguel Ángel de Quevedo regresó a México para incorporarse a la vida nacional, trabajando entre 1888 y 1900 para el gobierno porfirista. Sus labores técnicas como ingeniero auxiliar en las 
obras del desagüe del Valle de México, como director de obras portuarias en Veracruz y como consultor de diferentes empresas privadas de energía eléctrica le permitirían comprender empíricamente la relevancia de la conservación de los bosques en las cuencas para el porvenir de la nación. Para Quevedo los recursos silvícolas representaban el bienestar o la ruina de cualquier nación porque de estos dependía la estabilidad hidrológica y climática, así como la protección contra la erosión de los suelos cultivables. Su formación como ingeniero le permitió adquirir una amplia perspectiva de los graves problemas que acarreaba a mediano y largo plazo el uso, abuso y destrucción de la cubierta forestal del país, lo que a su vez le daría claridad para impulsar uno de los proyectos más ambiciosos y complejos de nuestra historia. En este orden de ideas podemos decir que fue la perspectiva técnica y no política la que determinaría las acciones gubernamentales encaminadas a la conservación hidrológica forestal de las cuencas del territorio nacional: fueron los ingenieros quienes comprendieron la importancia que estas y sus masas forestales tenían para el porvenir de la nación y de las futuras generaciones.

El ingeniero Quevedo y Zubieta reconoció durante toda su vida que fue el curso de "Hidráulica Agrícola y Sanitaria", impartido por Alfredo Durand Claye en la Escuela de Puentes y Calzadas, lo que le permitió comprender la trascendencia de los bosques para la agricultura, la industria y la higiene pública; en otras palabras, las distintas funciones que brindaban a la vida y al desarrollo de los seres humanos. Esto nos permite exponer que fueron los conocimientos técnicos en hidráulica la base sobre la cual sustentaría muchos de sus planteamientos conservacionistas.

En 1889, por solicitud del Presidente y los Vocales de la Junta Directiva del Desagüe del Valle de México, el ingeniero Quevedo preparó un estudio sobre la historia del Desagüe, mismo que acompañaba la colección de dibujos técnicos que serían presentados en la Exposición Universal de París de 1890. En este trabajo Quevedo expuso que los desmontes efectuados por los españoles en las serranías y laderas de la cuenca del Valle habían provocado terribles consecuencias, debido a que los bosques eran responsables de mantener la frescura y humedad de la atmósfera y regular el curso de las aguas. Don Miguel Ángel de Quevedo argumentó que los españoles, con el objetivo de "elevar sobre pilotes la nueva capital, ó 
enemigos de las plantaciones, para hacer del Valle una tierra semejante a la árida Castilla, pronto lo transformaron", lo cual provocó en la región central y norte terribles consecuencias ${ }^{14}$. En este contexto expuso que:

"Al desmonte de las laderas y serranías del Norte y Centro del Valle, á su aridez, siguió, pues, la formación de torrentes destrozadores, la esterilidad, sequía y pobreza de su planicie. Esta es una ley general que, en nuestro territorio, dada su topografía y la distribución de las lluvias, se manifiesta con mayor vigor, causando en menor tiempo mayores ruinas" $"$.

Los trabajos técnicos que desarrolló el ingeniero Quevedo le permitieron elaborar un diagnóstico claro sobre el impacto que tenía la conservación de los bosques, en un país como México, en tres niveles: agrícola, industrial y el biológico, en el que se incluían las variables de estabilidad climática e hidrológica del territorio.

En junio de 1899 fue publicada en los Anales de la Asociación de Ingenieros y Arquitectos de México la "Memoria sobre las empresas de fuerza motriz eléctrica, de aguas para abasto de poblaciones y del ferrocarril de Monte-Alto, pertenecientes á la Compañía de San Idelfonso, S. A., y anexas actualmente á la fábrica de tejidos de lana de este nombre". En este trabajo podemos observar la perspectiva que consideraba a las cuencas como unidades productivas para el desarrollo industrial y, por consecuencia, sujeta a la conservación forestal.

Miguel Ángel de Quevedo tenía claros los problemas que se presentaban por la pérdida de la cubierta forestal, y expuso que:

"A fin de evitarlo la Compañía adquirió los terrenos en que brotan los principales manantiales, y posee actualmente 30 caballerías de bosque en la cuenca superior del río Monte-Alto; tiene además celebrados contratos con los propietarios de los otros

14 Miguel Ángel de Quevedo, Memoria sobre el Valle de México, su Desagüe y Saneamiento (México: Oficina Tip. de la Secretaría de Fomento, 1889).

15 Miguel Ángel de Quevedo, Memoria sobre el Valle, 37. 
montes en que brotan las demás aguas del mismo río, quienes se comprometen á no derivar ni gastar esas aguas, á no desmontar los terrenos inmediatos á los manantiales, y facultan a la Compañía para que en cualquier tiempo pueda hacer dichos terrenos las obras que á ella convengan para el aumento ó conservación de las mismas aguas. [...] La adquisición hecha por la Compañía, de la referida extensión de terrenos cubiertos de bosque y en que nacen las principales corrientes de agua, asegura de por sí la conservación de éstas con la misma conservación de los bosques y su aumento. En la cuenca del río Tlanepantla el peligro señalado es mucho menor, porque los manantiales no pueden ser con la misma facilidad utilizados en el riego de los terrenos en que nacen; sin embargo, también allí se ajustan actualmente contratos y compras semejantes á los ajustados en la cuenca del Monte-Alto"

Para Quevedo la única posibilidad viable, técnica y económicamente, para que la Ciudad de México y las zonas industriales del país, ubicadas en Veracruz, Puebla, Guadalajara y el Estado de México, contaran con un suministro estable de energía y agua para cubrir sus necesidades industriales era la conservación forestal de las cuencas hidrológicas. Podemos decir que la perspectiva conservacionista de los ingenieros mexicanos se sustentaba en la trascendencia de la conservación hidrológica forestal.

Esta perspectiva se hizo patente durante los Congresos de Meteorología. En los salones de la Sociedad Antonio Alzate, a las 10 de la mañana del martes 17 de diciembre de 1901, fue inaugurado el Segundo Congreso Mexicano de Meteorología, y el día jueves 19 participó el ingeniero Miguel Ángel de Quevedo con la ponencia intitulada "Conveniencia de estudiar todas las circunstancias en que se distribuye el agua pluvial que cae en las varias cuencas del territorio; de coordinar las observaciones pluviométricas con las de hidrometría en las mismas cuencas, así como también de abasto de poblaciones y del ferrocarril de Monte-Alto, pertenecientes á la Compañía de San Idelfonso, S. A., y anexas actualmente á la fábrica de tejidos de lana de este nombre". Anales de la Asociación de Ingenieros y Arquitectos de México, México, t. VIII, (1889), 121-122. 
que se expidan las leyes conducentes á la conservación y repoblación de los bosques en el Territorio"17. La insistencia en que el Estado promulgara una Ley Forestal nacional seguía presente y fue una demanda que los conservacionistas no verían cristalizada hasta 1926.

En diciembre de 1902 se realizó el Tercer Congreso Meteorológico Nacional, evento en el que se presentó el informe y las gestiones hechas por la Comisión de Climatología aplicada a la agricultura. El último día de 1902 Quevedo le informó al entonces Ministro de Hacienda José Yves Limantour sobre sus actividades en los dos últimos Congresos de Meteorología. Por vía epistolar le expuso que desde el Segundo Congreso fueron aprobadas diferentes medidas entre las que se encontraba la conformación de una comisión de trabajo permanente que gestionaría con las Secretarías de Estado la expedición de una legislación para conservar y repoblar los bosques en las cuencas hidrológicas ${ }^{18}$.

La misiva de Quevedo incluyó la ponencia que presentó en el Tercer Congreso, intitulada "Importante acción de los bosques sobre la circulación de agua en la superficie de los continentes". El 5 de enero de 1903 el Ministro Limantour respondió al ingeniero Quevedo exponiéndole que compartía plenamente sus ideas sobre la conveniencia de poblar de árboles el mayor número de terrenos y exponía que "no necesita Ud., por lo mismo, convencerme de la importancia que para México tienen las obras que se emprendan en este sentido, y por mi parte, estoy enteramente dispuesto á tomar en consideración, cualquier proyecto práctico que se me presente para ese objeto"19.

Hay que señalar que a partir de ese momento las cuencas hidrológicas, su conservación y repoblación forestal, se convirtieron en el eje que articularía el proyecto de la segunda generación de conservacionistas mexica-

17 s/a, "Segundo Congreso Meteorológico Nacional. Sesión de la mañana de ayer. Presidencia del señor Ingeniero D. Manuel Pastrana, Director del Observatorio Meteorológico Central. La predicción del tiempo", El País, México, 20 de diciembre de 1901, 1.

18 (México, 31 de diciembre de 1902) Archivo del Centro de Estudios Históricos de México (A-CEHM), fondo CDLIV, caja 13/legajo 5/ f. 6.

19 (México, 31 de diciembre de 1902) A-CEHM, fondo CDLIV, caja 13/legajo 5/ f. 6. 
nos. Fue a partir de los congresos meteorológicos que por primera vez en la historia de México se delinearon las primeras directrices técnicas para resolver un problema que día con día se agravaba. En este sentido podemos decir que ese año puede ser considerado el punto de inflexión que marcaría una ruptura con todos los esfuerzos decimonónicos: la política conservacionista del siglo XX en México tendría por fin un grupo que la dirigiera, encabezado por Miguel Ángel de Quevedo.

En 1903 fueron publicadas las recomendaciones hechas por la Comisión Permanente de Climatología, documento en el que se hizo explícito que la conservación y repoblación de los bosques en las cuencas hidrológicas era fundamental para la agricultura, la industria y la climatología del territorio nacional. Por tales motivos se expuso que:

"A fin de que los beneficios señalados en la proposición anterior se obtengan de una manera más pronta y eficaz, el Congreso reconoce la necesidad de que los Poderes Públicos expidan, á la mayor brevedad posible, la legislación que se tiene ya estudiada sobre conservación y repoblación de los bosques en el Territorio nacional" 20 .

Los conservacionistas mexicanos, tanto de la primera generación como de la segunda, creyeron que uno de los aspectos torales que lograría articular una política exitosa de conservación forestal era la expedición de una ley de carácter nacional en la materia. Ese punto se puede ver reflejado en el siguiente argumento expuesto por el ingeniero Quevedo, donde se incluyen también aspectos de salud pública:

"la urgencia de que los Supremos Poderes dicten la legislación que venga á poner coto a los graves males que trae consigo la tala de los bosques y la falta de repoblación [...] los males indicados llegan ya hasta el extremo de hacer cambiar con grave perjuicio la

20 Miguel Ángel de Quevedo, Comisión Permanente de Climatología y sus Aplicaciones a la Agricultura nombrada por el Tercer Congreso Meteorológico Nacional. Documentos, relativos al estudio de las lluvias en su relación con la hidrografía de las varias cuencas del Territorio y a la conservación y repoblación de los bosques (México: Oficina Tipográfica de la Secretaría de Fomento, 1903), 28. 
climatología é higiene de importantes regiones del país. [...] en el hermoso y rico Valle de Orizaba cuya climatología ha cambiado de manera notable en muy pocos años, haciéndose ya hoy habitable esa región para el mosquito transmisor de la fiebre amarilla, que antes tenía como barrera la frescura de esa alta zona, acusándose á la vez muy notables aumentos en la temperatura y una disminución considerable en el estado hidrométrico de la atmósfera y en el caudal de las aguas corrientes"21.

Una de las propuestas presentadas por la Comisión Permanente de Climatología fue la conformación de una Junta encargada de desarrollar los trabajos encaminados a implementar una serie de medidas para hacer frente al problema.

En septiembre de 1904 fue creada por el Ministro de Fomento, el general González de Cosío, la Junta Central de Bosques correspondiente al Distrito Federal. Estaba incorporada a la Sección $5^{a}$ de la Secretaría de Fomento, que era responsable de las secciones de Agricultura y Aguas. Los miembros que la integraron eran: el ingeniero agrónomo Manuel Vera, el agricultor Jacinto Pimentel y Fagoaga, el ingeniero Guillermo Beltrán y Puga, el licenciado Indalecio Sánchez Gavito hijo, el agricultor Iñigo Noriega y el ingeniero del Cuerpo de Montes de España José de la Macorra ${ }^{22}$. Al ser constituida la Junta Central de Bosques como organismo encargado de gestionar e impulsar todos los esfuerzos que el Estado requería para limitar el uso, abuso y destrucción de los bosques e intentar remediar, con el trabajo humano, los males que afectaban el interés de la nación, emergía un nuevo paradigma de apropiación del territorio que tenía como objetivo garantizar el bienestar de las generaciones futuras.

Al finalizar ese año la Junta Central ya había establecido un programa de trabajo y definido las comisiones que lo desarrollarían en todo el país. En una entrevista publicada el 12 de noviembre en El Imparcial, el ingeniero Quevedo expuso que para poder resolver el problema de las talas inmo-

21 Miguel Ángel de Quevedo, Comisión Permanente de Climatología y, 37.

22 Miguel Ángel de Quevedo, “La Junta Central de Bosques”, Revista Forestal Mexicana, año 1, No. 1 (1909): 8. 
deradas y los males que de estas se derivaban, era fundamental expedir una legislación en cada entidad federal o en el Congreso general. Asimismo, explicaba que se estaban desarrollando los estudios necesarios con el propósito de hacer plantaciones forestales en las cuencas más adecuadas que estuvieran desprovistas de vegetación y exponía que: "Hay que agregar que dichos terrenos son además, causa de insalubridad y disminuyen la dureza de los terrenos más bajos de la misma cuenca, por los atierres perjudiciales que ocasionan en los últimos y la humedad que les quitan"23.

La Junta Central y sus miembros tenían un ambicioso proyecto: entendían la importancia de considerar el agua como inseparable de los bosques, porque sin el elemento forestal esta desaparecía, conocimiento que los llevó a proponer que se legislaran simultáneamente. De igual manera proponían que los ingenieros inspectores de aguas o ríos en las concesiones federales fueran al mismo tiempo inspectores de bosques, puesto que no se contaba con los recursos humanos acordes con la magnitud del problema. Por tal motivo era fundamental la formación, en la Escuela de Agricultura, de ingenieros especialistas en aguas y bosques ${ }^{24}$. Tenían claro que la zona con mayor degradación era la Mesa Central, donde en los últimos años se había alterado considerablemente el clima provocando sequías prolongadas. Por la suma de hechos Quevedo argumentaba a la prensa que "De todas estas consideraciones deduce la Junta Central que existe un fundamento incontrastable para expedir, por causa de utilidad pública una legislación especial de bosques, aunque sea preciso reformar la constitución política de la República"25.

La discusión quedaba abierta y como el problema era cada día más grave, el gobierno porfirista permitió que se comenzara a diseñar una propuesta de ley. A fines de 1904 la Junta Central ya se organizaba en distintas comisiones: para la formación de la carta forestal; para el estudio del proyecto de ley forestal; para el estudio comparativo de las legislaciones en otros países; para instituir las juntas en otros estados y organizar las medidas Mesa Central. El árbol y la higiene”, El Imparcial, México, 12 de noviembre de 1904, 1.

$24 \mathrm{~s} / \mathrm{a}$, "Propaganda para la conservación de los Bosques...1.

25 s/a, "Propaganda para la conservación de los Bosques... 1. 
mientras no se lograra legislar en la materia. Al finalizar ese año, la mayoría de los gobernadores había aceptado la invitación para colaborar con la Junta Central y comenzaban a designar a los responsables de las Juntas Locales de Bosques ${ }^{26}$.

El 18 de diciembre El Imparcial informaba a la opinión pública que en casi todos los estados de la República habían quedado constituidas las Juntas Locales, las cuales trabajarían en coordinación con la Central para dar continuidad a los trabajos de conservación de los bosques. La misma nota explicaba que se habían integrado expertos en agronomía y que también estaban colaborando la Academia de Medicina, el Consejo Superior de Salubridad, la Academia Mexicana de Jurisprudencia, la Sociedad Científica Antonio Alzate y la Sociedad Agrícola Mexicana. Las reuniones que realizaba la Junta eran en la "casa del señor Ingeniero D. Miguel Ángel de Quevedo para proseguir sus estudios de los documentos que servirán de base al programa general"'27.

El 17 de julio de 1905 el ingeniero Quevedo informaba que la comisión encargada de los estudios legales estaba a punto de terminar el Código Forestal, el cual sería sometido a su aprobación. Aseguraba que dicho documento estaría listo a finales de enero de 1906 y que debido a que "en vista de algunos informes suministrados posteriormente por algunas Juntas de los Estados habrá que rectificar ciertos puntos de la parte ya formada de la Carta Forestal, y en esta virtud, se retrasará aún por algunos meses, su presentación á la Secretaria de Fomento"28. Los logros por parte de los conservacionistas empezaban a verse reflejados en estas medidas instrumentadas por el Ejecutivo.

Las acciones en materia de gestión para impulsar algunas medidas administrativas habían dado ciertos resultados, como la gestión ante la Secretaría de Hacienda para que se prohibieran las adjudicaciones de terrenos en las Municipalidades del Distrito Federal y se comenzaran a reservar para

26 s/a, "Protección de los Bosques", El Tiempo, México, 7 de diciembre de 1904, s/p.

27 s/a, "Repoblación de Bosques. Siguen los trabajos", El Imparcial, México, 18 de diciembre de 1904, 1 .

28 "La Junta Central de Bosques. Importantes labores", El Tiempo, México, 17 de junio de 1905, s/p. 
bosques nacionales. Otras medidas fueron la recuperación de los terrenos ya adjudicados y la de otros para iniciar la repoblación del arbolado y aumentar las masas forestales en las serranías que rodeaban el Valle ${ }^{29}$.

El 30 de marzo de 1907 el ingeniero Quevedo le informó a Limantour: "voy a Europa de mis expensas, embarcándome en el próximo vapor francés que sale de Veracruz el 12 de abril, para estudiar en Argelia, España, Francia, Suiza y Alemania tanto la organización del servicio y personal forestales" 30 . Podemos afirmar que durante ese viaje de estudios el ingeniero Quevedo obtuvo una perspectiva más amplia y compleja sobre los asuntos forestales relacionados con la hidrología.

Mientras estuvo en Europa informaba de manera regular a los distintos ministros sobre sus estudios forestales, urbanos y de higiene. Su estancia en París, durante el mes de junio, la enfocó a estudiar el servicio forestal francés y localizar al personal especializado que se contrataría para trabajar en México. Debido a que el Sr. Bouvar, Director de Obras Públicas de París, se encontraba de viaje en Argentina, fue el famoso forestal y jardinero paisajista Nicolas Forestier el encargado de guiar a Quevedo durante su estancia en la ciudad, donde se concentró en el estudio del sistema de higiene, aguas, vías públicas, jardines y arbolados. En aquella estancia también recibió apoyo del ingeniero Daubrée, entonces Director del Servicio de Aguas y Bosques en el Ministerio de Agricultura, quien le proporcionó un programa de estudios que le permitiría a Quevedo contar con los elementos necesarios para la formación del servicio forestal nacional en México:

"En pocos días estudiaré la organización del servicio y de las escuelas especiales de Barres y Nancy que visitaré para seguir con los trabajos de repoblación en los Alpes, Argelia y venir al Puy de Dôme en donde tengo que detenerme algunos días para una cura, seguiré después á una expedición por los Pirineos y España, cuyo servicio forestal estudiaré también para continuar con el de Alemania; en septiembre asistiré en Berlín al congreso internacional de Higiene, proponiéndome á la vez estudiar los di-

30 (México, 30 de marzo de 1907) A-CEHM, fondo CDLIV, carpeta 21/ legajo 243, / f. 5. 
versos servicios públicos de tan importante capital para regresar en Octubre" 31 .

Después de regresar de Europa y estudiar los distintos servicios forestales, la perspectiva de Quevedo se amplió en todos los sentidos: observó los importantes trabajos de repoblación en los Bajos Alpes y con angustia constató la ruina y miseria en la que se encontraba España, notó el deterioro de sus montañas y campos de la inmensa zona central debido a la tala de sus bosques ${ }^{32}$. Don Miguel Ángel de Quevedo, después de asistir al Congreso Internacional de Higiene y Urbanismo celebrado en Berlín, donde se retomarían los temas acordados en 1900 en París, haría suya la propuesta de aquel Congreso de proporcionar a las grandes ciudades reservas forestales, las cuales debían rodearlas y tener aproximadamente una extensión de 10 kilómetros. Aquel viaje le permitió reforzar algunas tesis que ya había postulado desde sus trabajos para la Compañía de San Ildefonso, así como exponer otras que complementaron su pensamiento conservacionista. En este sentido, podemos decir que las ideas de Quevedo estuvieron en constante desarrollo y avanzaban conforme a los problemas que se iban presentando; la mentalidad práctica del ingeniero le permitió estar en constante actualización en materia hidrológica forestal.

Es importante señalar que después de su estancia en Europa, en el mes de junio de 1908, presentó un informe al Secretario de Fomento intitulado La cuestión forestal en México y Medidas que conviene adoptar para su resolución. Informe rendido al Ciudadano Secretario de Fomento en el Mes de Junio de 1908 por el Presidente de la Junta Central de Bosques ${ }^{33}$. En ese documento expuso sus principales tesis sobre la problemática forestal en México y, desde su perspectiva, la forma de solucionarla.

En dicho informe están contenidas las ideas que Miguel Ángel de Quevedo presentó en el Congreso Norteamericano de Conservación, donde

31 (París, 14 de junio de 1907) A-CEHM fondo CDLIV, carpeta 25/ legajo 201/ f. 5.

32 (Lugano, 12 de septiembre 1907) A-CEHM fondo CDLIV, carpeta 21/ legajo 243/ f. 6

33 Miguel Ángel de Quevedo, La cuestión forestal en México y Medidas que conviene adoptar para su resolución. Informe rendido al Ciudadano Secretario de Fomento en el mes de junio de 1908 por el Presidente de la Junta Central de Bosques (México: Imprenta y Fototipia de la Secretaría de Fomento, 1909). 
se tomaron algunos acuerdos que marcarían definitivamente el desarrollo e institucionalización de la política hidrológica forestal mexicana hasta el último día de sus trabajos como Director del Departamento Autónomo Forestal de Caza y Pesca, en el gobierno cardenista.

Fue en este trabajo donde Quevedo planteó de forma abierta, y como funcionario público, que el Estado debía adquirir la capacidad de intervenir tanto en la propiedad particular como en la ejidal y comunal. Asimismo, expuso su perspectiva sobre la conservación en los distintos niveles en la que esta debía operar: agrícola, industrial y biológico, haciendo una distinción entre recursos renovables y no renovables. Podemos decir que los conservacionistas mexicanos, encabezados por Miguel Ángel de Quevedo, ya habían desarrollado un modelo de gestión hidrológica forestal acorde a las necesidades de nuestro territorio antes de celebrarse la Conferencia de Washington.

\section{La Conferencia de Washington y el paradigma meXicano de CONSERVACIÓN}

El 30 de diciembre de 1908 el Ministro de Hacienda José Yves Limantour recibió una carta del químico industrial norteamericano Edward R. Taylor, donde le comunicaba sobre el viaje que realizaría a México el señor Gifford Pinchot para invitar formalmente al gobierno mexicano a participar en la Conferencia Norteamericana de Conservación, que se celebraría en la ciudad de Washington en febrero del siguiente año ${ }^{34}$.

Transcurría el primer mes de 1909 y la noticia sobre la invitación que el gobierno norteamericano había extendido a nuestro país ya circulaba en la prensa. Durante las primeras semanas de enero distintos periódicos hicieron eco de la celebración de la Conferencia y el viaje de Pinchot a México. El día 20 de enero El Diario del Hogar publicó la nota intitulada "Llegó a México Mr. Gifford Pinchot", en la cual se explicaba que el objetivo de la visita era invitar al gobierno mexicano a participar en dicho evento. El viernes 22 de enero de 1909, al mediodía, el presidente Díaz recibió en

34 (Nueva York, 30 de diciembre de 1908) A-CEHM, Fondo CDLIV, carpeta 30 / leg. 141/ f. 1. 
sus oficinas al señor Pinchot, quedando formalizada la invitación emitida por el presidente Roosevelt. Por petición del embajador norteamericano David E. Thompson el sábado 22, a las 12 del día, Pinchot también fue recibido por Limantour. Con ambas reuniones quedó confirmada la participación de la Delegación Mexicana en la Conferencia de Washington ${ }^{35}$.

Sin lugar a dudas uno de los eventos más relevantes en materia de conservación durante la primera década del siglo XX fue la participación de la Delegación Mexicana en la Conferencia Internacional Norteamericana sobre Conservación de Recursos Naturales, celebrada en Washington del 18 al 24 de febrero $1909^{36}$. Aunque dicha Conferencia tuvo un carácter consultivo, fueron elaboradas algunas resoluciones que, desde mi punto de vista, servirían a Miguel Ángel de Quevedo para impulsar con mayor fuerza la conservación forestal de las cuencas hidrológicas, como se verá a continuación.

La perspectiva de Quevedo sobre la conservación de los elementos naturales era diferente y, podemos decir, más integral que la expuesta por norteamericanos y canadienses. Esto se debió a que el ingeniero tenía claras las diferencias topográficas, climáticas y políticas de nuestro país. En otras palabras, este enfoque fue resultado de muchos años de trabajos prácticos y conocimientos acumulados sobre las singularidades ambientales del territorio nacional. Una primera reflexión que hay que destacar es la diferenciación que formuló sobre los recursos naturales de acuerdo con tres categorías: los renovables, que eran los recursos forestales; los no renovables, donde incluyó los minerales y el petróleo, y los que son renovables como el agua y cuya regeneración no está en manos del ser humano porque depende de los fenómenos naturales ajenos a voluntad de las sociedades:

"No es, en efecto, tan exactamente aplicable el concepto de conservación á los elementos minerales y otros no regenerables [...]

35 Es posible que el embajador Thompson le solicitara a Limantour que se reuniera con Pinchot debido a la gran influencia que el ministro de hacienda de Porfirio Díaz tenía en la toma de decisiones del gobierno; en este sentido Thompson realizó todas las gestiones necesarias para que en la Conferencia participara una delegación mexicana la que le daría esta reunión y mostrar el liderazgo norteamericano en ella.

36 (México, 5 de febrero a 20 de marzo de 1909) A-CEHM, Fondo CDLIV, carpeta 20/ leg. 61/ f. 6. 
están consiguientemente llamados a desaparecer, y su conservación es, por lo mismo, en sentido absoluto utópica. Unicamente puede y debe tenderse, respecto de esa clase de recursos no regenerables, á que su consumo se haga de la manera más juiciosa y provechosa, evitando los desperdicios, para lograr su máxima duración dentro del mayor provecho" 37 .

En este sentido, don Miguel Ángel exponía que:

"Los recursos forestales son, por el contrario, regenerables por la acción del hombre, y su conservación es, por consiguiente, realizable dentro de su necesario consumo; para ellos, como para los demás elementos regenerables por la intervención humana, el concepto de conservación abarca grandísima importancia y fines prácticos, pues que sin esa intervención del hombre, para su regeneración, el consumo que él hace de ellos los agotará por completo" 38 .

Hay que destacar que esta perspectiva es fundamental para comprender los trabajos que impulsó Quevedo. La acción del ser humano era necesaria para la conservación porque sin este la tasa de renovación natural quedaba rebasada debido al índice de consumo de la sociedad. En este contexto, el ingeniero Quevedo y Zubieta puso sobre la mesa un debate, hace más de cien años, vigente para el conservacionismo contemporáneo. El trabajo humano era para Quevedo indispensable para alcanzar los objetivos de la conservación forestal de las cuencas hidrológicas. Pero el ingeniero también haría una distinción primordial poco conocida en la materia: le quedaba claro que la conservación de los bosques tenía distinto valor para los países presentes en la Conferencia, por lo que su ponencia expuso de forma clara que la intención del gobierno del Presidente T. Roosevelt de procurar la conservación de los recursos naturales del continente, era una iniciativa de altas miras. Sin embargo, señaló Quevedo, para México la conservación de los recursos forestales era la más importante porque estos eran los que más se dilapidaban y los que mayor falta le hacían a nuestro

38 Miguel Ángel de Quevedo, "Informe del delegado", 77. 
país. En este sentido, el ingeniero explicó en el pleno que de los elementos forestales:

“el que más falta nos viene haciendo y del que depende, en gran parte, el conveniente aprovechamiento ó explotación y aun la conservación de los otros elementos naturales, como son, la local producción de lluvias, las corrientes ó depósitos de agua, la riqueza de nuestro suelo agrícola, los animales silvestres y aun la explotación económica de nuestras grandes riquezas minerales que sin la suficiente provisión de maderas y de agua para fuerza motriz, se hace casi imposible" 39 .

Es en este contexto donde marca una diferencia clara entre lo que sería, con el paso de los años, el modelo conservacionista mexicano y el norteamericano:

"Es efectivamente en México mucho más necesaria que en vuestro país y en el Canadá la conservación y mejora de los elementos forestales, porque la mayor parte de nuestro territorio, comprendida dentro de la zona intertropical, no disfruta, como los territorios más al Norte, de lluvias y otros meteoros acuosos casi permanentes, sino sólo periódicamente, con largo intervalo de sequía, bajo un régimen torrencial que hace sumamente más perjudiciales y violentos los desastrosos efectos de la desforestación, á tal extremo que, si en aquellos países del Norte el problema forestal es meramente de orden económico, en nuestro país es asunto mucho más grave, porque es también cuestión de orden biológico, vinculada como lo está muy estrechamente á las condiciones de salubridad pública, de comodidad y demás que requiere la vida animal ó la habitabilidad del país. [...] en los Estados Unidos y en el Canadá, en cuyos territorios, como antes se ha dicho, la cuestión forestal es meramente de carácter económico, significando tan sólo tener más o menos riqueza maderable para las necesidades actuales y futuras; y, por lo que esta cuestión pue-

Miguel Ángel de Quevedo, "Informe del delegado...”, 78. 
de afectar a la hidrología y conservación de la riqueza agrícola en mucha menor escala que en México"40.

Quevedo expuso en la Conferencia que en el país era de toda urgencia dictar medidas adecuadas para garantizar la conservación y la explotación racional de los bosques, para lo cual la Junta Central de Bosques se encontraba gestionando una legislación forestal acorde con sus condiciones específicas. En dicha propuesta se consideraba la forma en que la autoridad debía legislar en materia silvícola, de acuerdo con los tipos de propiedad que había en México: señalaba la posibilidad de expropiar a los particulares, así como de decretar reservas forestales en los terrenos de propiedad nacional y municipal, restringiendo el fraccionamiento o distribución de los ejidos de los pueblos o de común repartimiento. En este contexto expuso que la Secretaría de Fomento había presentado un proyecto de ley para someter a un régimen forestal apropiado.

“de conservación y repoblación todas las cuencas hidrográficas, [...] la Comisión Forestal gestiona también que se expida, sin demora, una legislación aun más completa, abarcando la cuestión en toda su amplitud y detalles, [...] las necesidades hidrológicas, sino también la climatológica, salud pública, conservación y riqueza del suelo"41.

Esta cita nos permite mostrar que Quevedo tenía un proyecto sumamente ambicioso y claro en la materia. Estas ideas fueron expuestas durante todos los años en que trabajó a favor de la conservación hidrológica forestal. Por ahora queda destacar que los acuerdos tomados por la Conferencia contemplaron diversos aspectos que serían retomados por el ingeniero para justificar distintas medidas prácticas en diferentes etapas de la historia nacional.

$40 \quad$ Miguel Ángel de Quevedo, “Informe del delegado...," 78, 81.

41 La Redacción, "Resumen de la disertación del delegado mexicano Señor Ingeniero D. Miguel A. de Quevedo, sobre las condiciones forestales de México, ante la Conferencia internacional de la Conservación de los Recursos Naturales de Norte América, celebrada en Washington", Revista Forestal Mexicana, n. 4 (1909): 87-88. Los corchetes son míos. 
Las resoluciones de la Conferencia se dividieron en ocho apartados: declaración de principios, salud pública, selvas, aguas, tierras, minerales, protección de animales silvestres y de caza, y comisiones de conservación. Sin lugar a dudas todos los puntos de las resoluciones son interesantes e importantes empero, solamente retomaremos los que estén relacionados directamente con esta investigación. Hay que destacar que el espíritu de las resoluciones sirvió como guía para las políticas que el Estado aplicaría a los intereses particulares, cualidad significativa porque nos muestra una tendencia favorable que fue aprovechada por el liberalismo conservacionista mexicano que tuvo en Miguel Ángel de Quevedo su figura central durante la primera mitad del siglo XX.

La Declaración de Principios señaló que se reconocía como recursos naturales a todos los elementos aprovechables para el uso humano como medios de vida y bienestar que estuvieran contenidos en la superficie del globo: suelo, agua, bosques y los que se encontraran en el subsuelo, como los minerales. Se declaró que:

"Reconocemos que aquellos recursos, necesarios para la vida, deben considerarse de utilidad pública; que la propiedad de los mismos implica determinados deberes hacia el público, y que, en cuanto sea posible, deben adoptarse medidas eficaces para protegerlos contra todo monopolio perjudicial"42.

La perspectiva antimonopólica sobre la explotación de los recursos naturales solamente la podía garantizar el Estado; esto era evidente para los conservacionistas, ante el comportamiento histórico que los particulares habían tenido. Esa situación no era exclusiva de algún país, sino que fue una constante que se expresaba en todos, y que exigía la intervención del Estado por causa de utilidad pública. El tercer punto retomó las recomendaciones referentes a los bosques o selvas, reconociendo su importancia para la civilización y el bienestar público. Se consideró la necesidad de darles una utilidad juiciosa y protección eficaz, ya fueran de propiedad pública, colectiva o individual. Se estimaba sustancial realizar a la mayor

42 La Redacción, "Resumen de la disertación del delegado mexicano Señor Ingeniero D. Miguel A. de Quevedo...", 99. 
brevedad los inventarios forestales en todos los países involucrados en la Conferencia, lo cual permitiría proyectar los recursos disponibles y regular la capacidad de consumo humano y reproducción. Asimismo, se recomendó la difusión de educación técnica en la enseñanza práctica sobre la conservación, explotación y repoblación de los bosques, así como la conformación de un personal oficial competente que pudiera socializar sus conocimientos con la ciudadanía. Se consideró importante la creación de numerosas y extensas reservas de bosques, así como su conservación permanente bajo el control del Gobierno, dada su importancia para el bienestar público. La Conferencia también formuló las siguientes resoluciones en materia de cuencas hidrológicas:

"Convenimos en que la propiedad de terrenos forestales, ya sea en las cuencas que abastecen los ríos y arroyos, ó ya en las tierras mejor adaptadas para la silvicultura que para otros usos, implica deberes hacia el público, y en que esos terrenos deben protegerse con igual eficacia, ya sean de propiedad pública ó privada. [...] Como las selvas son necesarias para proteger los manantiales de los ríos, moderar las inundaciones, regularizar las corrientes de las aguas, templar el clima y proteger el suelo, convenimos en que todas las selvas necesarias para estos propósitos deben ser eficazmente resguardadas. Reconocemos la necesidad absoluta de reservar para bosques todas las cuencas superiores que abastecen los ríos, y en consecuencia recomendamos el control ó adquisición públicos de dichos terrenos para los fines indicados" ${ }^{43}$.

En cuanto a las resoluciones referentes a la explotación de los minerales, la Conferencia declaró que se debía "favorecer el empleo de la fuerza motriz de agua con relación particularmente á la del vapor ú otra fuerza producida por el consumo de combustible" 4 .

Estos acuerdos de carácter consultivo serían aprovechados por Quevedo para impulsar sus ideas y proyectos conservacionistas. Todavía en Was-

43 La Redacción, "Resumen de la disertación del delegado mexicano Señor Ingeniero D. Miguel A. de Quevedo", 101. Los corchetes son míos.

44 La Redacción, "Resumen de la disertación del delegado mexicano Señor Ingeniero D. Miguel A. de Quevedo...", 106. 
hington, le informó al Secretario Limantour que la participación de la delegación mexicana había estado a la altura de las circunstancias y que los resultados de la Conferencia habían sido muy positivos. De igual manera, el ingeniero le comunicó que demoraría su regreso al país porque pasaría algunos días estudiando con el Sr. Pinchot algunos aspectos del Servicio Forestal Americano ${ }^{45}$. Los acuerdos tomados en la Conferencia nos permiten demostrar que la preocupación por el deterioro de la naturaleza y sus ritmos de regeneración eran de carácter regional y no meramente nacional. Estos acuerdos internacionales ayudarían a presionar al gobierno de Porfirio Díaz para tomar acciones mucho más puntuales respecto a la conservación de las cuencas hidrológicas forestales.

A su regreso al país y durante todo el año de 1909, apoyado por miembros de la Junta Central de Bosques, el ingeniero Quevedo gestionó en los distintos niveles de la administración pública la aprobación de la Ley de Tierras de diciembre de 1909 y la Ley de Servicios Agrícolas Federales promulgada el 27 de diciembre del mismo año. Estas leyes fueron los mecanismos jurídicos administrativos con los que se contaría para implementar la política de conservación hidrológica forestal de las cuencas nacionales hasta la aprobación de la Ley Forestal de 1926.

La propuesta de ley aprobada por la Cámara cambió de forma radical respecto a la que desarrollara años antes la Comisión nombrada por la Junta Central de Bosques. Hay que señalar que la iniciativa que presentó la Junta Central fue modificada por el Consejo de Ministros, y los cambios elaborados cancelaron la posibilidad de legislar conjuntamente los recursos silvícolas e hidrológicos desde la perspectiva de cuenca hidrológica forestal como unidad de conservación. No obstante, mantuvo en algunos aspectos la idea integral de Quevedo de englobar aguas y bosques como parte de un mismo proceso natural que se debía proteger. También hay que señalar que la puerta quedaría abierta en materia de regulación del Estado hacia los particulares, porque una de esas leyes contempló la expropiación por interés público a los particulares que usaban, abusaban y destruían el patrimonio forestal del país. En su artículo $46^{\circ}$ exponía que:

45 (Washington, 25 de febrero de 1909) A-CEHM., Fondo CDLIV, carpeta 20/leg. 61/f. 4. 
"El Ejecutivo podrá expropiar por causa de utilidad pública, los bosques y terrenos á que se refiere el artículo anterior, cuando á su juicio no se realicen la conservación, repoblación y regular explotación de los bosques y cuando la plantación de terrenos desnudos fuere necesaria para la conservación de los manantiales y corrientes de agua, ó conveniente por otros motivos de salubridad pública"46.

La reorganización administrativa marcaría el fin de un periodo positivo para la conservación forestal de las cuencas hidrológicas, el cual regresaría con toda su fuerza hasta la presidencia de Cárdenas. Sin embargo, los esfuerzos del ingeniero Quevedo no terminaron con este nuevo rumbo de la administración porfirista: sus trabajos seguirían desarrollándose, pero tal como lo relató a Limantour, lo harían en un ambiente hostil y sin muchas perspectivas de éxito. Podemos decir que la aprobación de la Ley de Servicios Agrícolas marcó el final de una etapa, junto con el movimiento revolucionario de 1910. Debido a los límites jurídicos impuestos por la Constitución de 1857, era imposible ir más lejos; sería necesaria una reorganización del andamiaje jurídico, que sostenía el pacto social mexicano, para lograr avanzar en un nuevo modelo de apropiación del territorio que permitiera impulsar un paradigma de conservación adecuado para México. No obstante, es necesario señalar que este modelo tendría constantes contradicciones.

Quevedo le explicó al exsecretario de Hacienda que la iniciativa del Ministro de Fomento de disolver la Junta Central de Bosques y crear un Departamento o Dirección Forestal para concederle más facultades y facilitar el desarrollo del plan de protección forestal, había tenido las mejores intenciones empero, los resultados de esta medida habían sido contrarios a los proyectos de conservación.

Quevedo expuso a Limantour que un grupo de agrónomos se oponía tanto a sus trabajos como a las gestiones que se venían haciendo para legislar y restringir el libre uso de los bosques por los particulares y municipios.

46 s/a, "Cámara de Diputados. Se aprueba un importante Proyecto de Ley", El País, México, 11 de diciembre, 1909, 2. 
Para el ingeniero, el hecho de que el ramo de bosques dependiera de la nueva Dirección de Agricultura estaba llevando al proyecto forestal a una situación desfavorable, ya que el director de Agricultura no le daba libertad para desarrollar los trabajos prácticos de reforestación, al grado de hostilizar al personal del Departamento Forestal, incluidos los brigadieres franceses a los que se amenazaba con rescindir sus contratos.

Las hostilidades ejercidas por parte del Director del Departamento de Agricultura hacia las actividades del Departamento, según la carta escrita a Limantour, habían llegado al extremo de intentar desaparecer el Vivero Principal y detener los trabajos en Veracruz, que ya estaban dando excelentes resultados. Para Quevedo esa situación se debía a la perspectiva exclusivamente agrícola que dominaba la política de la Secretaría de Fomento ${ }^{47}$. Podemos afirmar que en México la tensión histórica entre conservación hidrológica forestal y agricultura se puede observar claramente en este periodo. La petición de Quevedo dirigida a Limantour para que se le apoyara otorgándole autonomía al Departamento de Bosques sería una realidad hasta 25 años después, con el gobierno del general Cárdenas.

La perspectiva agrarista liberal, hostil a los proyectos del liberalismo conservacionista, se puede ver reflejada en el discurso pronunciado por don Luis Cabrera el 2 de diciembre de 1912 en la Cámara de Diputados, donde se expresó sobre las injustas medidas que el Departamento Forestal había tomado al reglamentar el uso de los bosques de Milpa Alta, Tlalpan y San Ángel ${ }^{48}$. Cabrera no poseía los conocimientos técnicos para comprender que la serranía del Ajusco no era capaz de sostener modelos agrarios a largo plazo. En un discurso en el que no da nombres, surge la duda de si ese alto funcionario que menciona pudo haber sido Quevedo.

La tensión en la que se encontraba el país, el poco apoyo recibido desde la salida de Limantour y las relaciones agrestes con Huerta fueron determinantes para que el ingeniero Quevedo renunciara; posteriormente saliera

47 (México, 10 de julio de 1910) A-CEHM, Fondo CDLIV, carpeta 24/ doc. 57/ f. 2.

48 Luis Cabrera, "Discurso de Luis Cabrera 2 de diciembre de 1912", en Expedición de la Ley Agraria. 6 de enero de 1915 (México: Comisión Nacional para las Celebraciones del 175 Aniversario de la Independencia Nacional y 75 Aniversario de la Revolución Mexicana-INEHRM, 1985), 38. 
al exilio y sus trabajos prácticos fueran suspendidos hasta la conformación de la Sociedad Forestal Mexicana.

\section{EL PROYECTO DE CONSERVACIÓN DE LAS CUENCAS HIDROLÓGICAS: 1917-1940}

El conservacionismo hidrológico forestal de las cuencas sería la garantía de que las futuras generaciones contaran con los recursos necesarios para el porvenir. Por tal motivo podemos decir que existe en el pensamiento de Quevedo una concepción de nación y de historia de largo aliento, un proyecto de futuro que podemos sintetizar retomando el siguiente postulado, expuesto por él en los meses previos al Constituyente de Querétaro:

'Y como los recursos naturales de la Nación, los bosques sobre todo que aún nos quedan, no reducirlos a propiedad privada, son el origen también de nuestras divisiones y codicias y causa, por su mal aprovechamiento, de inmenso perjuicio para la Nación, establezcamos asimismo en nuestra nueva Constitución la Reserva de todos esos bienes, en el concepto de que en lo sucesivo no se les explotará sino para el máximo provecho de la Nación"49.

De este modo, Quevedo hacía patente que la conservación del patrimonio natural era una responsabilidad de la sociedad en su conjunto con las futuras generaciones de mexicanos.

Se puede afirmar que el conservacionismo en México fue un proyecto que se propuso como objetivo heredar a las futuras generaciones un territorio que tuviera las condiciones necesarias para alcanzar un modelo exitoso de desarrollo; intentó resolver de manera práctica y duradera la tensión entre desarrollo y conservación, destacando el potencial del trabajo y no solo los recursos que la naturaleza le dio al país para ser explotados, como el petróleo y los minerales. En sus tesis, Quevedo diferenció entre recursos no renovables, los cuales debían ser utilizados de la forma más racional y eficiente posible, y los renovables, los cuales se tenían que conservar

49 Miguel Ángel de Quevedo, Consideraciones sobre nuestro problema agrario (México: Imprenta Victoria, 1916), 109. 
mediante el trabajo humano y así garantizar el porvenir. En este contexto los trabajos que desarrolló e impulsó durante toda su vida tuvieron como meta que el Estado contara con el instrumental jurídico necesario para alcanzar este objetivo. Así, el artículo 27 Constitucional y la primera Ley Forestal de 1926 fueron los mecanismos legales que permitirían garantizar el bienestar de las futuras generaciones ${ }^{50}$. Lo antes mencionado nos permite afirmar que si el liberalismo dio al ser humano las garantías individuales, el conservacionismo fue el pacto social que garantizó la responsabilidad y el compromiso que la nación tendría para entregar a las futuras generaciones trabajo y riqueza natural.

En el tomo segundo de su obra intitulada Geografía de la República Mexicana. Geografía Biológica y Geografía Humana, Don Jesús Galindo y Villa atribuyó al ingeniero Quevedo la perspectiva conservacionista del Artículo 27 de la Constitución Política y expuso que fueron las iniciativas y propuestas del ingeniero Quevedo:

“Ayudado también por el Ingeniero don JOSÉ DUVALÓN, Director de Agricultura y del Licenciado don ANDRÉS MOLINA ENRÍQUEZ, a quienes convenció de aquella necesidad se logró así que el artículo 27 Constitucional señalara no sólo las aguas y las tierras y minerales del territorio que deben protegerse, sino también los bosques y animales de caza y pesca, y, además, se añadió, que los bosques comunales y ejidales no son repartibles; e igualmente con relación a enseñanza y protección agrícola se incluyeron muchos de los consejos del folleto citado; lográndose en cuanto al reparto de tierras agrícolas, no fijar como se pretendía, el máximo de 500 hectáreas para la propiedad agrícola de particulares, sino dejar que en cada Estado el Gobierno Local definiera el límite de los latifundios" ${ }^{51}$.

50 La Ley Forestal de 1926 incorporó la perspectiva hidrológica en su Artículo 24: "Cuando el Ejecutivo estime que deba existir determinada vegetación en ciertos terrenos, debido a su situación, condiciones topográficas, hidrográficas, u otras causas, dispondrá, por su conducto de la Secretaría de Agricultura y Fomento, la ejecución de los trabajos necesarios de repoblación, fijación del terreno, corrección de torrentes, formación de dunas artificiales". "Ley Forestal", Diario Oficial (DOF), t. XXXV, n. 43 (1926): 1052.

51 Jesús Galindo y Villa, Geografía de la República Mexicana. Geografía Biológica y Geografía Humana, t. II (México: Sociedad de Edición y Librería Franco Americana S. A., 1927), 156. 
Esta referencia a la obra de don Jesús Galindo y Villa es una prueba de la importancia que jugaría en el diseño e implementación de las políticas gubernamentales el pensamiento del ingeniero Quevedo.

Al quedar estipulado en el Artículo 27 Constitucional que la nación tendría todo el derecho de imponer a la propiedad privada las modalidades que dictara el interés público, en los principios normativos también fueron contempladas las facultades de la nación para regular el aprovechamiento de los elementos naturales, su distribución equitativa, así como su conservación. La incorporación del concepto de "conservación" marcó un antes y un después en nuestra historia sobre la propiedad y la conservación de los recursos naturales: al facultar administrativamente al Estado para imponer límites en su uso, se intentó corregir el abuso y destrucción que los particulares podían hacer en su propiedad cuando afectara al interés público. En este orden de ideas, la Constitución Política incorporó una variable que permitió promover un proyecto nacional de conservación hidrológica forestal de las cuencas para impulsar el desarrollo nacional.

Como lo señaló Galindo y Villa, el papel de Quevedo en la concepción del Artículo 27 Constitucional es inobjetable tanto en su vertiente conservacionista como en la agraria. Esto se demuestra porque sus iniciativas en materia forestal, primero durante el porfiriato y posteriormente durante los gobiernos revolucionarios, fueron las únicas que abordaron el problema de la conservación de los recursos naturales en los distintos niveles de la administración pública. Lo cual se materializó en la protección hidrológica forestal de casi el $33 \%$ del territorio nacional gracias a la creación del Sistema de Reservas Forestales de propiedad de la nación, que alcanzó su mayor impulso durante el cardenismo.

Es importante dar algunos ejemplos, en materia de dotación de ejidos, que nos permitan demostrar cómo se incorporó la perspectiva conservacionista en las políticas agrarias. El 28 de diciembre de 1920, durante la presidencia de Álvaro Obregón, se promulgó la Ley de Ejidos. En el artículo octavo de esta normatividad se contempló que los fallos de las 242 autoridades agrarias, relacionados a dotaciones o restituciones de tierras, afectaban también a los bosques y montes. En el Capítulo II, Artículo $17^{\circ}$, quedó establecido que los bosques comprendidos en los ejidos serían 
de uso común, mientras no se legislara el fraccionamiento de las tierras reivindicadas u obtenidas. La Ley de Ejidos indicó puntualmente en el Capítulo VI las obligaciones de las Juntas de Aprovechamiento de los Ejidos:

"III.- La Junta de Aprovechamiento de los Ejidos tendrá por obligaciones:

c) Vigilar porque cumplan las leyes relativas a conservación de bosques, y prohibir, si fuere conveniente, la tala en los montes y campos, reglamentando la replantación de árboles útiles en cada ejido" 52 .

La primera Ley de Ejidos tenía como base constitucional la fracción sexta del Artículo 27. Es importante mencionar que las tesis conservacionistas se comenzaron a expresar en distintos niveles de la política pública. Por ejemplo, el lunes 20 de mayo de 1921 fue publicada en el Diario Oficial la resolución de restitución y dotación promovidas por los vecinos de Villa de Ocampo, donde se indicó en el Considerando sexto:

"Que la existencia de los bosques y arbolados es de ingente necesidad para asegurar las mejores condiciones climatéricas y meteorológicas del país y conservar una de las principales fuentes naturales de la riqueza pública; que para dar plena satisfacción a las necesidades sociales apuntadas se hace de todo punto necesaria la explotación en común de los terrenos forestales y el exacto cumplimiento de las leyes en la materia. Por estas consideraciones y a partir de la fecha de la actual resolución los vecinos de Villa de Ocampo quedan obligados a mantener, conservar y fomentar la vegetación forestal existente en la superficie de terreno que se les concede y a explotarla en común, aplicándose el producto de dicha explotación a los servicios públicos de la comunidad, en la inteligencia de que el cultivo que fuere susceptible el terreno de la parte arbolada del ejido, deberá sujetarse a las ordenaciones que sobre este particular contenga la Ley de Bosques respectiva"53.

52 "Ley de Ejidos", Cinco Siglos de Legislación Agraria en México (1493-1940), comp. Manuel Fabila (México: Procuraduría Agraria, 2005), 328-329.

53 DOF, t. XVIII, No. 24. México, 30 de mayo de 1921, 366. 
En su quinta resolución se exponía que "Los bosques existentes dentro de los terrenos dotados, se disfrutarán por los vecinos en los términos que expresa el Considerando sexto de esta resolución" 54 .

Este no sería un caso aislado. La política de Reforma Agraria incorporó las tesis conservacionistas que buscaban que las riquezas forestales se administraran correctamente por la comunidad, lo que permitiría, por una parte, mantener las condiciones climáticas e hidrológicas del territorio nacional y, por otra, brindar recursos para el sustento y beneficio de las comunidades indígenas campesinas. Podemos decir que la política agraria fue un modelo redistributivo de las riquezas forestales a las comunidades y contempló la conservación como un beneficio para la nación entera. A partir de esta perspectiva podemos enfocar el proceso agrario desde la justicia ambiental no solamente para los individuos o familias, sino para todo un país que se vio afectado por el uso, abuso y destrucción de sus recursos silvícolas y las consecuencias que este tuvo para el desarrollo nacional.

Fue hasta 1937 que se puede observar un nuevo giro en la materia ${ }^{55}$, lo que se explica por el decreto presidencial de 1937 en el que se expone que el lunes 7 de junio de 1937 fue publicado el Decreto Presidencial que declaraba inafectables en materia de dotaciones y restituciones agrarias a los Parques Nacionales. Hay que señalar que uno de los aspectos más importantes, como se podrá advertir, es que este Decreto retomó dos de los rasgos más distintivos del modelo conservacionista mexicano: el primero, la perspectiva sobre la importancia que estos espacios tenían para el desarrollo, considerando el potencial de las cabeceras de las cuencas para mantener ciertos servicios ambientales; y el segundo, la justicia social, la cual era entendida como la posibilidad de que los habitantes cercanos a la zona demarcada como Parque Nacional pudiera beneficiarse de algunos recursos sin afectar la estructura del mismo.

En la siguiente cita podemos apreciar algunas de las singularidades más importantes de lo que fue nuestro modelo de conservación como impulsor del desarrollo nacional: 
"CONSIDERANDO que los bosques de las más altas cumbres de las serranías, tienen un importante papel de protección contra la denudación del suelo, por lo general muy accidentado, y como mantenedores de las corrientes de agua en que ellos tienen origen y van a fecundar las tierras, regularizando a la vez su clima.

CONSIDERANDO que es urgente y necesario restaurar por la vía natural o, en su caso, por la artificial, el estado boscoso de esas cumbres para que presente los beneficios antes apuntados.

Acuerdo 1.- Los Parques Nacionales se declaran inafectables en materia de Dotaciones y Restituciones Ejidales [...] Acuerdo 2.- En todos los casos de tramitación de expedientes para la declaración de Parques Nacionales y en los que se refiere al aprovechamiento de pastos, maderas muertas y demás esquilmo que no perjudiquen ni destruyan los Parques Nacionales en beneficio exclusivo de los ejidos o núcleos de población rural inmediatos a los mismos, previamente se tomará en consideración al Departamento Agrario" 56 .

Este decreto modificaría las resoluciones de las Autoridades Agrarias en materia de dotación y restitución de ejidos a la población, porque incorporaría los acuerdos decretados el 7 de junio del 1937, los cuales se mantuvieron durante todo el sexenio cardenista.

En 1930 las resoluciones agrarias ya habían integrado que:

"Habiéndose declarado de utilidad pública la conservación y propagación de los bosques y arbolados en todo el Territorio Nacional, debe advertirse a la comunidad beneficiada con esta dotación la obligación que contrae de conservar, restaurar y propagar los bosques y arbolados que contengan los terrenos que se les conceden" 57 .

56 "Acuerdo que declara inafectables, en materia de dotaciones y restituciones ejidales los Parques $\mathrm{Na}$ cionales", Diario Oficial, México, t. CII, No. 23, 7 de junio 1937, 8.

57 "Resolución en el expediente de dotación de ejidos al poblado Benito Juárez, Territorio Norte de la Baja California", DOF, México, t. CII, No. 1, 1 de mayo de 1937, 9. 
Podemos observar algunas variaciones respecto a los decretos de la década de 1920, donde la conservación no era contemplada como de utilidad pública. También hay que señalar que en las consideraciones fueron eliminados los argumentos sobre los beneficios climatéricos y meteorológicos, así como la obligación de explotación común. Después de haberse decretado que los Parques Nacionales eran inafectables en materia de reparto y restituciones agrarias, de nueva cuenta los decretos fueron modificados, quedando explícitas las consideraciones de la nueva normatividad. Por ello es importante retomar uno de los decretos para ejemplificar el cambio, lo que nos permite ponderar hasta dónde llegó la influencia del Departamento Autónomo Forestal:

"La presente resolución debe considerarse como título comunal para el efecto de amparar y defender la extensión total de los terrenos que la misma comprende, a favor del poblado beneficiado, cuyos vecinos quedan obligados [...] a cumplir las disposiciones que dicte el Departamento Forestal por lo que se refiere a la conservación, restauración, propagación y explotación de sus bosques y arbolados. [...] Por lo tanto deben cooperar con las autoridades municipales, del Estado o de la Federación, en todo caso de incendio de bosques de su región, estándoles prohibido, en términos absolutos, ejecutar todo acto que destruya sus bosques y arbolados. [...] Les será autorizada la explotación de sus bosques cuando el Departamento Forestal los hay organizado en cooperativa forestal y cuando sean atendidos, en caso de que necesiten crédito, por la institución que señale el Gobierno Federal; quedando prohibido, con sanción de nulidad, todo acto o contrato que contravenga este punto del resolutivo, así como todo acto o contrato de venta o arrendamiento de sus montes en pie y la intervención de personas o empresas extrañas al ejido, en los casos de que se trata" 58 .

Hay que señalar que, según la fecha del Diario Oficial, la modificación fue inmediata a la expedición del Decreto del 7 de junio de 1937, la cual se

58 "Resolución en el expediente de ampliación de ejidos al poblado El Grullo, Estado de Jalisco", DOF, México, t. CIII, No. 1, $1^{\circ}$ de julio de 1937, 7. 
mantuvo durante toda la gestión de Cárdenas, pero dejaría de ser mencionada después de 1940, año en el que el presidente decidió cerrar el Departamento Autónomo.

Uno de los aportes más relevantes del conservacionismo a la política nacional fue la creación de un sistema de conservación hidrológico forestal en la Mesa Central del territorio. En este orden de ideas se expondrán algunos ejemplos que nos permitan dimensionar la magnitud del proyecto. Uno de los acuerdos más importante fue el de protección de las cuencas nacionales, que se dio el 3 de enero de 1934. Aquel día el presidente Abelardo L. Rodríguez declaró Zonas Protectoras Forestales los terrenos cubiertos de arbolado, situados en las cuencas hidrográficas de los Sistemas Nacionales de Riego en proyecto o construcción. Los Considerandos expuestos por el Ejecutivo eran que una de las políticas de mayor importancia para el Gobierno Federal eran los Sistemas Nacionales de Riego construidos o en construcción, porque "representan las obras de mayor costo o importancia para el desarrollo de los trabajos agrícolas de diversas regiones del país." Es necesario recordar que estas medidas fueron propuestas por Quevedo el 26 de diciembre de 1930 y la decisión de implementarlas fue tomada cuatro años después de haberse realizado los estudios.

Uno de los Considerandos nos permite observar cómo el modelo de irrigación posrevolucionario, igual que el proyecto agrarista y el proyecto energético para el desarrollo nacional, involucraron aspectos fundamentales del conservacionismo hidrológico-forestal pensando en el presente y el futuro. En este sentido se previó que era indispensable la conservación forestal de aquellas cuencas porque estando sujetos los vasos de almacenamiento a la influencia de las corrientes de agua que los alimentaban, resultaba conveniente mantener la regularidad de dichas aguas evitando que se generaran corrientes torrenciales que eran provocadas por la desforestación ${ }^{59}$.

59 "Acuerdo que declara Zonas Protectoras Forestales los terrenos cubiertos de arbolado, situados en las Cuencas Hidrográficas de los Sistemas Nacionales de Riego en construcción o proyecto", en Cinco Siglos de Legislación Agraria en México (1493-1940), comp. Manuel Fabila, 20-27. 
También es importante exponer que igual que muchas Reservas Forestales de la nación, a pesar de estar ubicadas donde había muchos núcleos de población, estas no eran restrictivas. Por ello es necesario retomar el tercer y cuarto Acuerdo:

"Tercero. El Servicio Forestal, con la ayuda de las demás dependencias del Ejecutivo, autoridades locales y sociedades u organizaciones particulares que estén en posibilidad de cooperar, formulará desde luego el programa general de reforestación en cada zona, para ponerlo en práctica en las regiones de las cuencas hidrológicas de los ríos y arroyos donde sea más urgente la restauración de la vegetación forestal.

Cuarto. El presente acuerdo no implica restricción alguna de los trabajos agrícolas o ganaderos siempre que no afecten terrenos cubiertos de arbolado de origen natural o artificial" ${ }^{60}$.

La intención de mantener y restaurar la cubierta forestal de los Sistemas Nacionales de Riego, según el acuerdo, incluiría diferentes actores, entre los cuales se encontraban los particulares. De esa manera el proyecto intentó tener un alcance nacional, entendido este como la conjunción del trabajo de autoridades, sectores sociales, empresariales y particulares. Hay que señalar que este acuerdo no excluyó las actividades agrícolas ni ganaderas, por lo que el conservacionismo intentó implementar un modelo incluyente donde las distintas actividades productivas se siguieran desarrollando.

En el cuadro ${ }^{61}$ que se presenta a continuación se da cuenta de los Sistemas de Irrigación, las cuencas y los estados que abarcaban, en las que se debía conservar y restaurar las masas forestales:

Quevedo señaló que las Reservas Forestales debían ser clasificadas en tres categorías. La primera era la de Reserva Forestal de Propiedad Nacional; la segunda, la modalidad de Parques Nacionales y la tercera, las Zonas Protectoras Forestales. Es importante señalar que cada una de las catego-

60 "Acuerdo que declara Zonas Protectoras Forestales los terrenos cubiertos de arbolado...", 20-27.

61 Elaboración propia. 


\begin{tabular}{|c|c|c|}
\hline Sistema Nacional de Riego & Cuencas & Estados \\
\hline $\begin{array}{l}\text { Sistema Nacional de Riego } \\
\text { Número } 1 \text { "Presidente Calles" }\end{array}$ & $\begin{array}{l}\text { Cuencas hidrográficas de los ríos } \\
\text { San Pedro, Pabellón, Santiago. }\end{array}$ & $\begin{array}{l}\text { Aguascalientes y } \\
\text { Zacatecas }\end{array}$ \\
\hline $\begin{array}{l}\text { Sistema Nacional de Riego } \\
\text { Número } 2 \text { "El Mante" }\end{array}$ & $\begin{array}{l}\text { Sierra Cucharas, Manantial "El Na- } \\
\text { cimiento" origen del río Mante }\end{array}$ & Tamaulipas \\
\hline $\begin{array}{l}\text { Sistema de Nacional de Riego } \\
\text { Número } 3\end{array}$ & $\begin{array}{l}\text { Cuencas hidrográficas del río Tepe- } \\
\text { ji, Salado, Tlautla tributarios del río } \\
\text { Tula }\end{array}$ & $\begin{array}{l}\text { Hidalgo, Edo. México, } \\
\text { Morelos, }\end{array}$ \\
\hline $\begin{array}{l}\text { Sistema Nacional de Riego } \\
\text { Números } 4 \text { y } 7\end{array}$ & $\begin{array}{l}\text { Cuencas hidrográficas superiores de } \\
\text { los ríos Salado de los Nadadores y } \\
\text { Sabinas, incluye sus afluentes }\end{array}$ & Coahuila \\
\hline $\begin{array}{l}\text { Sistema Nacional de Riego } \\
\text { Número } 5\end{array}$ & $\begin{array}{l}\text { Cuencas hidrográficas superiores de } \\
\text { los ríos Conchos, Nonoava, Balleza, } \\
\text { San Pedro, Chuviscar, Parral, Allen- } \\
\text { de y Florido }\end{array}$ & Chihuahua y Durango \\
\hline $\begin{array}{l}\text { Sistema Nacional de Riego } \\
\text { Número } 6\end{array}$ & $\begin{array}{l}\text { Cuenca hidrográfica de los arroyos } \\
\text { de Árboles y del León y sus afluen- } \\
\text { tes tributarios del río Bravo }\end{array}$ & Coahuila \\
\hline $\begin{array}{l}\text { Sistema Nacional de Riego } \\
\text { Número } 8\end{array}$ & $\begin{array}{l}\text { Cuencas hidrográficas superiores } \\
\text { del río Grande de Tulancingo y Ne- } \\
\text { gro incluyendo sus afluentes }\end{array}$ & Hidalgo \\
\hline $\begin{array}{l}\text { Sistema Nacional de Riego } \\
\text { Número } 9 \text { "Valle de Juárez" }\end{array}$ & $\begin{array}{l}\text { La Zona Federal del Río Bravo del } \\
\text { Norte }\end{array}$ & $\begin{array}{l}\text { Ciudad Juárez y } \\
\text { Chihuahua }\end{array}$ \\
\hline $\begin{array}{l}\text { Sistema Nacional de Riego } \\
\text { Número } 10\end{array}$ & $\begin{array}{l}\text { Cuencas hidrográficas superiores de } \\
\text { los ríos Hueyapan, Topia y Sianori, } \\
\text { incluyendo sus afluentes tributarios } \\
\text { del río Culiacán }\end{array}$ & $\begin{array}{l}\text { Chihuahua, Durango y } \\
\text { Sinaloa }\end{array}$ \\
\hline $\begin{array}{l}\text { Sistema Nacional de Riego } \\
\text { (sin número) }\end{array}$ & $\begin{array}{l}\text { Cuenca hidrográfica superior del río } \\
\text { Lerma, Cuenca de los ríos Tigre o } \\
\text { Coroneo, Querétaro, La Laja, Gua- } \\
\text { najuato, Silao, Turbio y Duero }\end{array}$ & $\begin{array}{l}\text { Edo. de México, } \\
\text { Michoacán, Guanajuato } \\
\text { y Querétaro }\end{array}$ \\
\hline $\begin{array}{l}\text { Sistema Nacional de Riego } \\
\text { (sin número) }\end{array}$ & $\begin{array}{l}\text { Cuencas hidrográficas de los ríos } \\
\text { Salinas o Pesquería y San Juan }\end{array}$ & Coahuila y Nuevo León \\
\hline $\begin{array}{l}\text { Sistema Nacional de Riego } \\
\text { (sin número) }\end{array}$ & $\begin{array}{l}\text { Cuenca superior del río Yaqui, inclu- } \\
\text { yendo sus afluentes }\end{array}$ & Chihuahua y Sonora \\
\hline
\end{tabular}

rías cumplía una función particular, pero hay que exponer también que el principal objetivo de estas era mantener el equilibrio biológico y económico del país; impulsar el desarrollo agrícola e industrial y fomentar el 
bienestar biológico nacional. En este contexto explicó que los bosques eran indispensables para cubrir el suelo, de tal manera que cumplieran con sus beneficios de orden, hidráulico, climatérico y de sana atmósfera, que son los beneficios de provecho público indiscutible. Los argumentos técnicos que dio eran simples y claros: la invasión de cultivos agrícolas a terrenos montañosos o en declive impropios para la producción agrícola habían provocado, desde tiempo de griegos y romanos, la ruina y desastre, así como la migración, ya que comarcas enteras se convierten en desiertos.

Hay que señalar que de 1917 a 1926 se habían decretado nueve reservas forestales, mientras que de 1926 a 1940 la cantidad aumentó a $108^{62}$. El número total de Reservas decretadas, en el periodo señalado, es un indicador de que la política de conservación hidrológica forestal del territorio, apoyada en el Artículo 27 Constitucional y en la Ley Forestal de 1926, puede ser considerada exitosa.

El primero de enero de 1940 Lázaro Cárdenas dio la instrucción de que el Departamento Autónomo Forestal fuera extinto y este ramo de la administración se integrara de nueva cuenta al Departamento de Agricultura. Sin embargo, los logros alcanzados por Quevedo y el grupo que lo acompañó durante este periodo son inobjetables. Por ejemplo, la superficie de conservación de las Reservas Forestales fue de 608.614 hectáreas y la que alcanzaron los Parques Nacionales fue de 514.446 hectáreas. Los ingresos del Departamento fueron incrementándose mientras se iba consolidado: durante el primer año el presupuesto asignado fue de poco más de 2 millones de pesos y los ingresos fueron de 1 millón 800 mil; para 1938 el presupuesto fue de 3 millones de pesos y los ingresos alcanzaron la cifra de 12 millones 200 mil pesos.

Otros datos que nos permiten dar cuenta del esfuerzo emprendido por la segunda generación de conservacionistas mexicanos son los siguientes: En materia de infraestructura desarrollada por el Departamento, y de acuerdo con datos presentados en 1934, en ese año había solo dos viveros

62 En este total están integradas todas las categorías de reserva incluyendo parques nacionales y la mayoría de estas se ubicaron en la Mesa Central, conformando el sistema hidrológico-forestal de conservación. 
gubernamentales, mientras que de 1935 a 1939 fueron creados 294 en toda la República, los cuales producían 10.865.218 árboles con los que se habían emprendido los trabajos de reforestación en diversas cuencas muy deterioradas. El contraste con los trabajos anteriores es muy ilustrativo, puesto que en el año de 1934 la Secretaría de Agricultura plantó 1.000 árboles y el Departamento en su corta existencia alcanzó la cifra de 6 millones 337.464 árboles, y solamente en la Cuenca del Valle de México la cantidad de 2 millones 143 mil. Otro de los grandes logros fueron los más de 4 mil viveros escolares que antes no existían ${ }^{63}$.

Al finalizar este artículo se presenta un mapa donde el lector podrá ubicar el área total de Reservas Forestales decretadas hasta 1940. Es importante advertir que también se incluyen las fuentes de producción de energía eléctrica así como las áreas forestales de reserva de los sistemas de riego. Con este mapa se muestra la correlación entre cuencas, densidad poblacional, desarrollo industrial y agrícola y conservación hidrológica forestal, lo que nos permite tener una perspectiva panorámica del proyecto encabezado por el ingeniero Quevedo y Zubieta.

\section{CONClusiones}

Antes de ser realizada la Conferencia Norteamericana de Conservación de los Recursos Naturales, en México ya se había desarrollado un enfoque de conservación que respondía a las necesidades ambientales específicas de nuestro país. Desde 1889 esta perspectiva consideró que eran las cuencas hidrológicas las áreas prioritarias de conservación porque de estas dependía el desarrollo agrícola e industrial de la nación.

La conservación en México fue integrada al marco jurídico, como se puede observar en el Artículo 27 de la Constitución de 1917 y en la Ley Forestal de 1926, además de formar parte de la política agraria de los gobiernos post-revolucionarios. En este orden de ideas se puede decir que el proyecto conservacionista fue un proyecto integral que intentó impulsar un modelo de desarrollo basado en un paradigma que comprendió la importancia hidrológica forestal de las cuencas nacionales.

63 Boletines del Departamento Autónomo Forestal y de Caza y Pesca de 1935 a 1939. 
Mapa $1^{64}$

Sistema de conservación hidrológica forestal (1940)

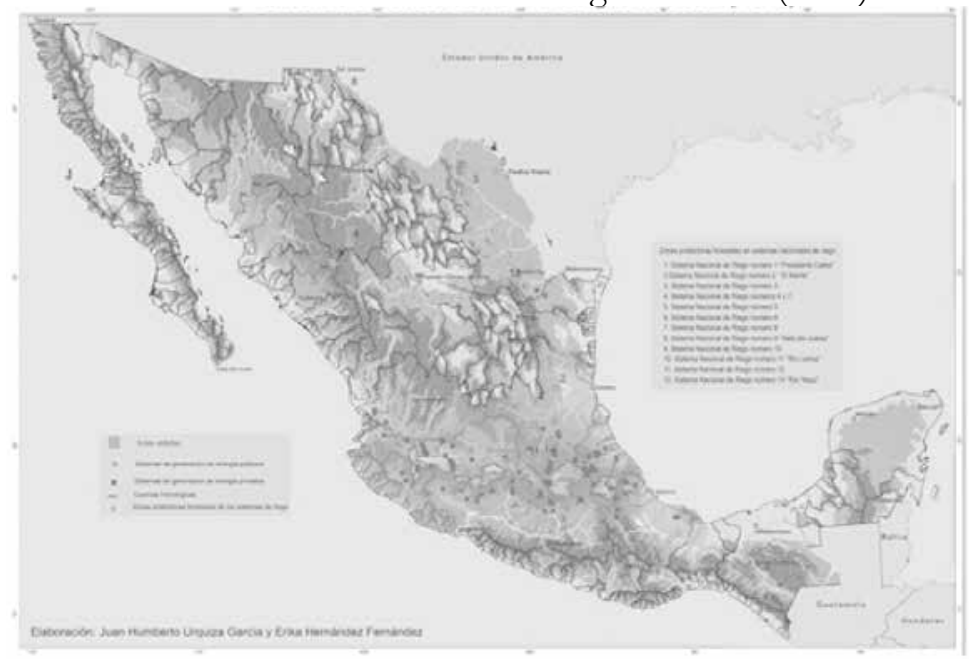

Fuente: Elaboración Juan Humberto Urquiza García y

Erika Hernández Fernández

\section{Bibliografía}

\section{Archivos}

Archivo del Centro de Estudios Históricos de México Grupo Carso ACEHM.

Diario Oficial de la Federación-DOF.

\section{Publicaciones periódicas}

"Acuerdo que declara inafectables, en materia de dotaciones y restituciones ejidales los Parques Nacionales”. DOF, México, t. CII, No. 23, 7 de junio 1937, 8.

"La Junta Central de Bosques. Importantes labores", El Tiempo, México, 17 de junio de 1905, s/p.

$64 \quad$ Este mapa, de elaboración propia, representa las Reservas Forestales, las fuentes de producción de energía eléctrica y las áreas forestales de reserva de los Sistemas Nacionales de Riego hasta 1940. Es importante explicar al lector que un mapa que contraste las Áreas Naturales Protegidas en la actualidad rebasa los límites historiográficos de este trabajo y las ANP decretadas durante las décadas siguientes ya no siguieron, en su mayoría, el modelo de conservación de las cuencas. 
“Ley Forestal". Diario Oficial (DOF), t. XXXV, n. 43 (1926): 1052.

"Resolución en el expediente de ampliación de ejidos al poblado El Grullo, Estado de Jalisco". DOF, México, t. CIII, No. $1,1^{\circ}$ de julio de $1937,7$.

"Resolución en el expediente de dotación de ejidos al poblado Benito Juárez, Territorio Norte de la Baja California”. DOF, México, t. CII, No. $1,1^{\circ}$ de mayo de $1937,9$.

Bustamante Rocha, Pio. Discurso sobre el establecimiento de la vegetación en la superficie del globo. México: El Siglo XIX, 29 de mayo de $1851, \mathrm{~s} / \mathrm{p}$.

DOF, t. XVIII, No. 24. México, 30 de mayo de 1926, 366.

DOF, t. XVIII, No. 24. México, 30 de mayo de 1921, 366.

Epstein, Isidoro. "La Tala inmoderada de los Montes. Estudio y proposiciones leídos en la Sociedad de Geografía y Estadística, por su autor, en la sesión del 5 de septiembre del presente”, El Nacional, México, 10 de abril de 1894, 2.

Hinojosa, Gabriel. Memoria sobre la utilidad de los bosques. México: El Siglo XIX, 31 de agosto de 1874, 1-2.

La Redacción. "Resumen de la disertación del delegado mexicano señor ingeniero D. Miguel A. de Quevedo, sobre las condiciones forestales de México, ante la Conferencia internacional de la Conservación de los Recursos Naturales de Norte América, celebrada en Washington". Revista Forestal Mexicana, n. 4 (1909): 87-88.

Payno, Manuel. "Bosques y Arbolados", Boletín de la Sociedad Mexicana de Geografía y Estadística, 2a. Época, t. II (1870): 77-91.

Quevedo, Miguel Ángel de. “Informe del delegado”. Revista Forestal, No. 4 (1909): 77.

Quevedo, Miguel Ángel de. “La Junta Central de Bosques”, Revista Forestal Mexicana, año 1, No. 1 (1909): 8.

Quevedo, Miguel Ángel de. "Memoria sobre las empresas de fuerza motriz eléctrica, de aguas para abasto de poblaciones y del ferrocarril de Monte-Alto, pertenecientes á la Compañía de San Idelfonso, S. A., y anexas actualmente á la fábrica de tejidos de lana de este nombre". En Anales de la Asociación de Ingenieros y Arquitectos de México, México, t. VIII (1889): 121-122.

Ramírez, Ignacio, Gumersindo Mendoza, Luis Malanco, Ignacio Cornejo. "Bosques y Arbolados", Boletín de la Sociedad Mexicana de Geografía y Estadística, 2a . Época, t. II (1870): 14-24. 
s/a. "Cámara de Diputados. Se aprueba un importante Proyecto de Ley". El País, México, 11 de diciembre, 1909, 2.

s/a. "Propaganda para la conservación de los Bosques. Acuerdos y observaciones. Las sequías en la Mesa Central. El árbol y la higiene”. El Imparcial, México, 12 de noviembre de 1904, 1.

s/a. "Protección de los Bosques". El Tiempo, México, 7 de diciembre de 1904, s/p.

s/a. "Repoblación de Bosques. Siguen los trabajos". El Imparcial, México, 18 de diciembre de 1904, 1.

s/a. "Segundo Congreso Meteorológico Nacional. Sesión de la mañana de ayer. Presidencia del señor ingeniero D. Manuel Pastrana, Director del Observatorio Meteorológico Central. La predicción del tiempo”. El País, México, 20 de diciembre de 1901, 1.

\section{Libros}

"Acuerdo que declara Zonas Protectoras Forestales los terrenos cubiertos de arbolado, situados en las Cuencas Hidrográficas de los Sistemas Nacionales de Riego en construcción o proyecto”. En Cinco Siglos de Legislación Agraria en México (1493-1940), comp. Manuel Fabila. México: Procuraduría Agraria, 2005, 20-27.

“Ley de Ejidos". En Cinco Siglos de Legislación Agraria en México (14931940), comp. Manuel Fabila. México: Procuraduría Agraria, 2005, 328-329.

Almaraz, Ramón. Memorias de los trabajos ejecutados por la Comisión Científica de Pachuca en el año de 1864. México: Imprenta de J. M. Andrade y F. Escalante, 1865.

Alzate y Ramírez, José Antonio. Proyecto del Br. José Alzate Ramírez sobre el descubrimiento y uso del carbón mineral (transcripción). México: Cuadernos de Quipu, 1988.

Bárcena, Mariano. Silvicultura. Breves consideraciones sobre explotación y formación de los Bosques. Estudio Presentado a la Secretaría de Fomento. Tepic: Tipografía de la V. de Legas, 1892.

Cabrera, Luis. "Discurso de Luis Cabrera 2 de diciembre de 1912". En Expedición de la Ley Agraria. 6 de enero de 1915. México: Comisión Nacional para las Celebraciones del 175 Aniversario de la Independencia Nacional y 75 Aniversario de la Revolución MexicanaINEHRM, 1985. 
Frey, Eugenio. Utilidad de los Bosques. Estudio Presentado a la Secretaría de Fomento en 1882. México: Imprenta y Fototipia de la Secretaría de Fomento, 1907.

Galindo y Villa, Jesús. Geografía de la República Mexicana. Geografía Biológica y Geografía Humana, t. II. México: Sociedad de Edición y Librería Franco Americana S. A., 1927.

Quevedo, Miguel Ángel de. Comisión Permanente de Climatología y sus Aplicaciones a la Agricultura nombrada por el Tercer Congreso Meteorológico Nacional. Documentos, relativos al estudio de las lluvias en su relación con la hidrografía de las varias cuencas del territorio y a la conservación y repoblación de los bosques. México: Oficina Tipográfica de la Secretaría de Fomento, 1903.

Quevedo, Miguel Ángel de. La cuestión forestal en México y Medidas que conviene adoptar para su resolución. Informe rendido al Ciudadano Secretario de Fomento en el mes de junio de 1908 por el Presidente de la Junta Central de Bosques. México: Imprenta y Fototipia de la Secretaría de Fomento, 1909.

Quevedo, Miguel Ángel de. Memoria sobre el Valle de México, su Desagüe y Saneamiento. México: Oficina Tipográfica de la Secretaría de Fomento, 1889.

Quevedo, Miguel Ángel de. Consideraciones sobre nuestro problema agrario. México: Imprenta Victoria, 1916.

Río de la Loza, Leopoldo. "Proyecto de Ordenanzas de bosques, de arbolados y de exportación de maderas”. En Escritos de Leopoldo Río de la Loza, compilado por Juan Manuel Noriega. México: Secretaría de Instrucción Pública y Bellas Artes, Imprenta de Ignacio Escalante, 1911, 335-347.

Villada, Manuel y Eduardo Armendariz. Concurso científico. Sociedad de Historia Natural. Discursos publicados en la sesión del día $1^{\circ}$ de agosto de 1895. México: Oficina Tipográfica de la Secretaría de Fomento, 1895.

Para citar este artículo: Urquiza García, Juan Humberto. "Miguel Ángel de Quevedo y el proyecto de conservación hidrológica forestal de las cuencas nacionales de la primera mitad del siglo XX, 1900-1940", Historia Caribe Vol. X No. 26 (Enero-Junio 2015): 211-255. DOI: http://dx.doi. org/10.15648/hc.26.2015.8 